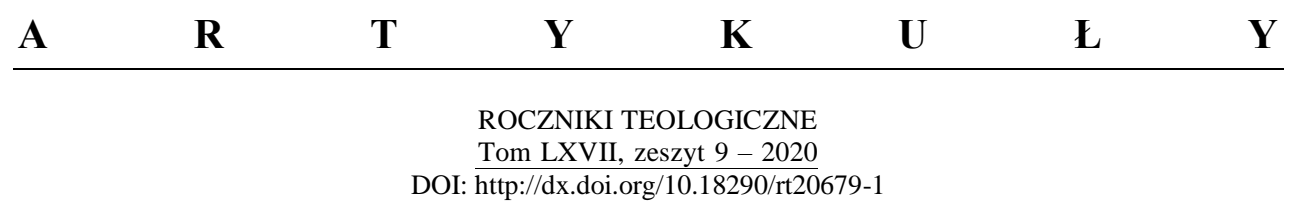

HANS WALDENFELS SJ

\title{
KONTEXTUELL UND OFFEN FÜR DIE WEITE UND DAS NEUE
}

\author{
HUMAN PLURALITY AND FINITUDE AND DIVINE INFINITENESS \\ AND OPENNESS FOR THE MAIUS AND THE NEW
}

\begin{abstract}
Descartes' slogan "Cogito ergo sum" determines modern thinking by emphasizing the "ego". Consequently, many people, living in their individual concrete historical setting, tend to become the absolute subjects and masters of their own lives, with their thinking and behavior independent of any other. We call the various factors of their biography - place and date of birth, gender, language, profession, religious affiliation, etc. - "the context", a term that we borrow from modern biblical exegesis. The vast plurality of egos, however, makes us aware of the existence of innumerable other egos, which - from one's own point of view - are non-egos; we call them "you" or "we".

Subsequently, the development of modern Western thought is described in view of the concept of "a person". In the Western thought "a person" is mainly understood as an individual, although in medieval philosophy and theology, it implies individuality and relationality. The difficulty of translation of the term "person" in different cultural surroundings is demonstrated with reference to the Japanese language.

We reach the full understanding of other people only if we come to know their limitations, especially in science and technology, and if we restore our sense of the infinite. The Canadian philosopher Charles Taylor reminds us that, in today's world, not all people have completely abandoned their faith of God and live by radical self-determination, but that there are still quite a few who expect their fulfilment in a life of selflessness, embedded in the hope for a new life to come from the Totally-Other, which we call "God", and working in solidarity for reconciliation, peace and justice.
\end{abstract}

Key words: Ego and non-ego; context; person; translation; European and other cultures; secular age; science and technology; future and advent; depth and width; openness; the new.

HANS WALDENFELS SJ - Professor em. Dr. Dr. Dr. h. c., Essen; e-mail: hans.waldenfels@t-online.de 


\section{ICH UND NICHT-ICH}

Der Beginn der abendländischen Neuzeit wird vielfach mit Descartes" Formel „Cogito ergo sum “, „Ich denke, darum bin ich“ und der darin verborgenen Betonung des Ich verbunden. Wer „Ich“ sagt, eröffnet damit den Blick auf eine unendliche Zahl von Möglichkeiten. „Ich“ kann männlich oder weiblich, inzwischen sogar in offiziellen Dokumenten weder männlich-noch weiblich sein, eine ursprüngliche Nationalität besitzen, aber diese später wechseln, eine Muttersprache haben, aber meine ursprüngliche Sprache ändern und in mehreren Sprachen zu Hause sein. Dasselbe gilt für die berufliche Tätigkeit, für die Zugehörigkeit zu einer religiösen oder weltanschaulichen Institution und vieles andere. „Ich“ kann zu einer religiösen Gemeinschaft gehören, muss es aber nicht, kann sie wechseln, inzwischen gelegentlich sogar zu mehreren Gemeinschaften gehören, wie man selbstverständlich zu mehreren gesellschaftlichen Vereinen gehören kann. „Ich“ verwirklicht sich in einer bunten Vielzahl unendlicher Möglichkeiten.

Jedes Ich hat seinen zeitlichen Ort in der Geschichte der Menschheit, kann aber den räumlichen Ort, an dem er/sie/es lebt, arbeitet und sich aufhält, ändern; wie es auch seinen Standpunkt; seine Meinung ändern kann. Das eröffnet Chancen, und viele Menschen empfinden es als ungeheures Freiheitspotential.

Ein spezifischer Ort, an dem die angesprochenen Möglichkeiten in besonderer Weise entdeckt wurden, ist die Literatur; in der abendländischen Welt interessanterweise nicht zuletzt die christliche Heilige Schrift, die Bibel $^{1}$. Wir haben einen Text, lesen ihn, hören ihn, suchen ihn zu verstehen. Lange Zeit begnügte man sich mit dem Text, wie er vorlag und machte sich seine eigenen Gedanken. Doch inzwischen geht es längst nicht mehr nur um den vorhandenen Text allein, sondern auch um das, was verborgen mit ihm zusammenhängt. Wir sprechen von „Kontexten“; dem Autor, der Autorin ${ }^{2}$, der Zeit, in der sie gelebt haben mit all den Zügen, die wir bereits angedeutet haben: der Lebenszeit, dem Lebensort, den Intentionen, die ein Autor mit seinen Texten verfolgt hat, was er sagen wollte. Dazu gehört die Geschichte der Entstehung eines Textes, aber auch die Geschichte seines Verstehens, die

\footnotetext{
${ }^{1}$ Vgl. zum Folgenden mein grundlegendes Werk: Kontextuelle Fundamentaltheologie (Paderborn: Verlag Schöningh, 2005 ${ }^{4}$ ) das Werk liegt inzwischen in neun Sprachen vor; polnisch: O Bogu, Jezusie Chrystusie i Kościele - dzisiaj (Katowice: Św. Jacka, 1993).

${ }^{2}$ Ich vermeide aus Gründen der Lesbarkeit im Folgenden den ständigen Wechsel des Geschlechts.
} 
Rezeptionsgeschichte, also die Geschichte; die ein Text in der Folgezeit durchmacht.

Die Entdeckung der Kontexte in der Literatur und die Beschäftigung mit ihnen, aber auch den Kontexten des Lebens der Menschen überhaupt sind einerseits ein großes Geschenk, bergen aber zugleich große Gefahren. Denn über der Entdeckung kann es leicht geschehen, dass der „Text“ in seinen eigentlichen Aussagen vergessen wird. So besteht bei der Beschäftigung mit den Kontextfaktoren die Gefahr, dass über der Vielzahl sich aufdrängender Momente im Einzelnen der Blick für die Einheit und Gemeinsamkeit der Menschheit und das Ganze der Welt verloren geht. Wir sitzen aber alle in einem Boot, und wenn wir über den Tellerrand des eigenen Lebens hinausschauen, müssen wir zugeben: Wir gehen nicht nur als einzelne Ichs auf ein Ende, sprich: den Tod zu. Nur als Ganzes von Menschheit und Welt werden wir überleben oder nicht. Wir stehen vor einem Abgrund, der so oder so ein Nicht-Ich ist.

Ich hatte das Glück, fast zehn Jahre meines Lebens in Japan, also einer völlig anderen Kultur zu verbringen und dort im Philosophen Kejji Nishitani (1900 - 1990) einen Lehrer eigener Güte zu finden und durch ihn mit der Kyoto-Schule in Kontakt zu kommen. Er öffnete meine Augen über die vielen Gestalten des Nicht-Ich hinweg für das absolute Nichts in seiner positiven Gestalt und damit auch für das Nicht-Ich überhaupt ${ }^{3}$.

Keiji Nishitani hatte früh Kontakte zu Deutschland, seiner Philosophie, aber auch seiner Mystik, zu Martin Heidegger und den Theologen in Marburg, wusste um Nietzsche, aber auch die Rheinische Mystik, zumal Meister Eckhart. Ich durfte in seinem Schülerkreis erleben, wie er mit seinen Schülern mystische Texte in der Ursprache las. Er wusste um biblische Texte wie den Galaterbrief des Paulus 2,20: „Nicht mehr ich lebe, sondern Christus lebt in mir.“ Doch auf die Frage Nishitanis: „Wer aber spricht denn da?“ wussten die Theologen in Basel und Marburg offensichtlich keine Antwort.

\footnotetext{
${ }^{3}$ Vgl. Hans WaLdenfels, Absolutes Nichts. Zur Grundlegung des Dialogs zwischen Buddhismus und Christentum. Mit einem Geleitwort von Keiji Nishitani (Freiburg: Herder, 1976); erweiterte Neuausgabe Paderborn: Bonifatius-Verlag, 2013; auch: „In Erinnerung an „Sensei“: Keiji Nishitani (1900-1990)“, in DERS., Rückwärts blickend vorwärts schauen. Zeitbetrachtungen zu Christentum und Menschsein, Religionen, Kulturen und Gesellschaft. (Theologische Versuche Bd.4) (Paderborn: Bonifatius-Verlag, 2016), 317-322.
} 


\section{DAS PROBLEMFELD „PERSON“}

In seinem international bekanntesten Werk Shūkyō towa nanika, deutsch: Was ist Religion (Insel-Verlag: Frankfurt 1982) schreibt Nishitani über das abendländische Personverständnis: „Ohne Zweifel ist der Begriff des Menschen als Person der höchste Begriff vom Menschen, den es bisher gegeben hat. Das gleiche kann vom Begriff Gottes als eines personalen Wesens gesagt werden. Seitdem in der Neuzeit die Subjektivität mit ihrem Selbstbewusstsein in den Vordergrund rückte, wurde der Begriff des Menschen als Person nahezu selbsteinsichtig. Ist aber die Art und Weise, über 'Person' zu denken, wie sie bis heute allgemein vorgeherrscht hat, wirklich der einzig mögliche Weg, über 'Person' zu denken?“" (130)

Hier kann nicht die komplexe Geschichte des Person-Begriffs nachgezeichnet werden. Doch ist auf einige Momente der Geschichte hinzuweisen:

- Die etymologische Ableitung aus dem Theater, nach der die Person ein durch eine Maske sprechender Schauspieler ist, ist äußerst fragwürdig.

- Der Begriff ist wesentlich in der abendländischen Philosophie beheimatet.

- Einflussreich war lange die Definition der Person durch den Philosophen Boethius aus dem 5. Jh. Danach ist „Person“ die unteilbare (,individuelle“) Substanz rationaler (vernünftiger) Natur (lateinisch: Persona est rationalis naturae individua substantia). Wichtig ist hier die Betonung der Individualität.

- Wo christlich-theologisch von drei göttlichen Personen die Rede ist, ist der philosophische Ansatz unbrauchbar; da drei Substanzen aus dem einen personalen Gott drei Götter machen würden. Tatsächlich wurde in der frühmittelalterlichen Theologie aus der Dreipersonalität Gottes ein Relationsgefüge.

- Während in der Neuzeit im Abendland der Akzent weithin auf der Individualität lag, kam es dennoch auch zu einer Person-Konzeption, in der beides die Individualität und die Relationalität -, also die Ich-Du-Wir-Beziehungen ihre Berücksichtigung fanden.

Im Ergebnis müssen wir feststellen, dass für die westliche Welt lange überwiegend das einzelne Ich, seine Würde und seine Rechte im Vordergrund standen, ja dass es de facto für viele Menschen immer noch der Fall ist. Die Betonung des einzelnen Ich führt aber zu Egoismus und Egozentrik und impliziert die Isolation des Einzelnen, ohne dass zunächst die Folgen bedacht und erkannt werden.

Wie schwierig ein Person-Denken außerhalb Europas ist, habe ich in meinen Dharmaram-Vorlesungen ausgeführt, die ich im Frühjahr 2011 im indischen Bangalore gehalten habe. Die Vorlesungen standen unter der Überschrift 
In-Between und bezeichneten den Menschen als ein „Wesen-dazwischen“. Die Grundthese lautete: Jeder einzelne Mensch lebt zwischen anderen Wesen ${ }^{4}$. Erläutert habe ich es an einem in Japan gebräuchlichen Wort für „Mensch“, ningen.

Hier muss man wissen, dass der Japaner über einen gewissen Reichtum an Schreibmöglichkeiten verfügt. Er benutzt einmal aus dem Chinesischen übernommene Bildzeichen (Kanji) ${ }^{5}$, sodann zwei eigenständige Silbenschriften (Hiragana und Katakana), schließlich die Umschrift in das europäische Alphabet (Romaji).

Ningen, mit zwei chinesischen Bildzeichen geschrieben, besteht aus nin = ein laufender Mensch + gen $=$ ein Tor, durch das die Sonne scheint, mit der Bedeutung „dazwischen“; der Mensch ist also ein Wesen, das dazwischen lebt.

Schwierig wird es mit der Übersetzung „Person“. Sie lautet im Japanischen jinkaku und schreibt sich jin $=$ Mensch $+k a k u=$ Charakter, Gestalt. Was philosophisch möglich ist, ist jedoch theologisch, wenn es um die christliche Theologie geht, völlig unmöglich. Denn ein allein die menschliche Personalität wiedergebender Begriff muss in Japan den theologischen Gehalt völlig verfehlen, ja unverständlich machen.

Um die hier angedeuteten Aspekte eines schwierigen Übersetzungsvorgangs sollte man wissen, wenn man in China den Vorwurf erhebt, dort würden ständig die Menschenwürde und Menschenrechte verletzt.

Westliche Menschen wissen zumeist kaum, wie schwierig es umgekehrt ist, die grundlegenden Begriffe der asiatischen Denkwelt aus dem Sanskrit und Pali, dem Chinesischen, Japanischen und Koreanischen in westliche Sprachen zu übersetzen. Dabei lassen wir Afrika und andere Kontinente völlig aus.

Jedenfalls dürfte klar sein: Der asiatische Mensch ist viel stärker geprägt durch das Bewusstsein, in einer Welt-dazwischen, zusammen mit anderen Lebewesen zu leben. Er lebt relational, somit anders als der westliche Mensch, der heute erschreckt vor den Gefährdungen seiner Umwelt steht und nicht laut genug über Klimakatastrophen klagen kann, ja inzwischen den Umgang mit diesen Gefährdungen für die wichtigste Aufgabe der Politik, der Ökonomie und der Zivilgesellschaft hält.

\footnotetext{
${ }^{4}$ Vgl. meine Veröffentlichung: In-Between. Essays in Intercultural and Interreligious Dialogue (Bangalore: Dharmaram Publications, 2011), vor allem Kap. 1.

${ }^{5}$ Der Umgang mit der Bilderschrift kompliziert sich, wenn man bedenkt, dass die einzelnen Zeichen unterschiedliche Lesarten zulassen. Das ist bei dem auch in jinkaku= Person gebräuchlichen ersten Zeichen jin der Fall. Es ist dasselbe wie nin in ningen. Man liest aber nin und jin.
} 


\section{GRENZEN DER WISSENSCHAFT UND TECHNIK}

Wohl die wichtigste Konsequenz der radikalen Hinwendung zum Ich als dem letztlich entscheidenden und über alles verfügenden Subjekt ist das von Menschen erarbeitete Wissen in Wissenschaft und Technik. Dabei überwog lange das Bewusstsein, aktives und nicht auch passives Subjekt zu sein. Das lässt sich leicht am Begriff der „Erfahrung“ erläutern (dazu KF 160-167).

Wir „machen“ Erfahrungen und verstehen „machen“ weithin aktiv. Dabei wird übersehen, dass „machen“ doppeldeutig ist. Einerseits machen wir Erfahrungen im Experiment, in dem wir selbst aktiv die Bedingungen erstellen, unter denen etwas geschieht oder versucht wird. Andererseits „machen“ wir Erfahrungen, die an uns geschehen, in denen wir passiv Empfangende sind. Wir sprechen dann von Widerfahrnissen. Diese werden zu oft als solche übersehen.

Das wirkt sich heute in hohem Maße aus, wo es um die Klimafrage geht. Das Klima ändert sich. Das Eis schmilzt an den Polen. Wir erleben Taifune und Tsunami, Vulkanausbrüche, Hitzeperioden ohne Regen und Zeiten der Überschwemmung. Zur selben Zeit treibt der Mensch Raubbau an den Wäldern. Er entdeckt die Vermüllung der Meere, Plastik in sterbenden Fischen. Viele Tierarten sind zum Aussterben verurteilt.

Der Mensch steigert die Automatismen im Leben, ist dabei, selbstfahrende Autos ohne Chauffeur zu produzieren, fliegt zum Mond, und möchte zum Mars. Viele Aktionen kann er längst durch die künstliche Intelligenz von Robotern ersetzen, - so sehr, dass es ihn inzwischen ängstigt.

Wir haben den Protest der Jungen. Theoretisch möchten viele aus den Städten die Autos verbannen, doch wo sie unmittelbar betroffen sind, möchte der Einzelne dann kaum auf den Komfort des Autos verzichten. Ähnliches gilt für den Flugverkehr.

Richtig ist sicher, dass der Mensch zur Einsicht kommt: Vieles, was auf unserer Erde falsch läuft, geht auf ihn selbst zurück, weil er maßlos ist, sich selbst überschätzt und seine Grenzen nicht sieht - Grenzen, die auch den Wissenschaften und der Technik gesetzt sind.

Diese Maßlosigkeit zeigt sich aber auch da, wo der Mensch den Menschen für alles verantwortlich macht. Bei allen Schäden, die wir der Natur und dem Menschen selbst, der ja ein Stück dieser Natur ist, zufügen, durchläuft die Natur ihre eigenen Prozesse, die der Mensch nicht beeinflussen kann. Insofern haben die gesellschaftlichen Kreise Recht, die von nichtmenschlichen Faktoren in den Klimaveränderungen ausgehen. Sie haben jedoch 
kein Recht, wenn sie den Menschen für schuldlos erklären wollen, wenn es um die Klimafragen geht.

Hier darf man fragen, warum es immer um ein Entweder-oder gehen muss und das Recht nicht auf je eigene Weise auf verschiedenen Seiten sein kann. Leider ist die Freiheit des Anderen nach wie vor für viele nicht die Grenze der eigenen Freiheit, die Sicht des Anderen kein Anlass zur Überprüfung und Korrektur der eigenen Sichtweise. Folglich ist die Tendenz zur eigenen Rechthaberei groß.

Neben den klimatologisch-ökologischen Fragen verdient der bioethisch-medizinische Bereich verstärkte Aufmerksamkeit, zumal wenn es um den Beginn und das Ende des Lebens geht. Abgesehen vom emanzipatorischen Slogan „Der Bauch gehört mir“" gibt es eine Vielzahl von Motivationen, die eine Abtreibung werdenden Lebens selbst medizinisch zu rechtfertigen scheinen. Die Zahl der Abtreibungen allein in Deutschland wird für 2018 mit 100986 angegeben. „Schutz des Lebens“ ist, wenn es konkret wird, oft ein leeres Wort.

Umstritten ist am Ende des Lebens die eigenmächtige Verfügung über Zeitpunkt und Umgang mit dem eigenen Tod, zumal wenn um eine aktive Sterbehilfe durch einen Arzt oder sonst wie verfügbaren Helfer geworben wird. Geht es nicht im eigenen Land, kann man oft einfach ins Nachbarland fahren.

Im Übrigen verschwimmen inzwischen immer mehr die Grenzen zwischen Menschen und Tieren. Bezeichnend war zum Jahresende 2019 in Deutschland der Umgang mit den aufgrund eines fahrlässigen Umgangs mit umstrittenen Feuerwerkskörpern im abgebrannten Affenhaus des Krefelder Zoos umgekommenen ca. 30 Affen. Berichtet und getrauert wurde über das Ereignis wie bei schweren Flugzeug- und Verkehrsunfällen und bei Opfern von Terrorangriffen; es wurden Blumen und Kerzen aufgestellt. Es ging um unsere Verwandten, wie es in der Presse hieß.

Brisant ist die verbreitete Einschätzung des menschlichen Körpers. Einem anderen Menschen zur Ermöglichung längeren Lebens oder gar des Überlebens aus dem eigenen gesunden oder toten Körper ein Organ zu spenden, ist ein legitimer und begrüßenswerter Vorgang. Er kann ein Akt aktiver Liebe sein. Doch ist es Sache des Staates, einen solchen Akt zu verfügen? Es ist erfreulich, dass der deutsche Bundestag sich am 16. Januar 2020 mit überwältigender Mehrheit für eine Zustimmungslösung und gegen die heftig propagierte Widerspruchslösung entschieden hat. Es macht doch einen entscheidenden Unterschied, ob ich mich selbst entschließe und meinen Körper im Falle eines Hirntodes zur Entnahme von bestimmten Organen zugunsten anderer freigebe oder ob ich das durch einen eigens bekundeten Willensakt ausschließen muss. 
Hier stellt sich die Frage nach dem Menschsein und der Würde seines Körpers ganz neu. Ist der Körper am Ende nicht mehr als eine geistlose materielle Organreserve? Wo die Rhetorik sonst von Freiheit und Würde überfließt, muss sich der Mensch gerade an den Grenzen menschlichen Lebens dem sonst laut vertretenen Anspruch stellen. Die grenzenlose Selbstüberschätzung des Menschen findet am Anfang und am Ende des Lebens seine Grenze, da beides - der Anfang, aber auch das vermeintlich selbst gesetzte Ende - ihm in Wirklichkeit entzogen ist.

Was hier beschrieben wird, hat eine unerwartete Bestätigung gefunden in der durch die Verbreitung des Corona-Virus ausgelöste Pandemie, die die ganze Welt erschüttert und in Aufruhr versetzt. Es ist, als ob viele Träume der Menschen zusammenbrechen würden. Hilflos und ohnmächtig schauen wir zu, wie unendlich viele Menschen kurzfristig in aller Welt an diesem Virus erkranken und zugrunde gehen. Die Frage ist jetzt auch: Was helfen uns die Religionen?

\section{SÄKULARES ZEITALTER}

Die Prozesse des Übergangs von einer vom Gottesglauben geprägten Gesellschaft zu einer Gesellschaft verbreiteter Wissenschaftsgläubigkeit, wurde lange mit dem Begriff „Säkularisierung“ beschrieben. Darin nehmen Gott und Religion eine sich ändernde Stellung ein. So ist Gott wie ein Uhrmacher, der eine Uhr aufzieht und sie dann laufen lässt (so die Vertreter des Deismus). Für Immanuel Kant (1724-1804) ist Gott ein Postulat der praktischen Vernunft. Auf Friedrich II. von Preußen (1712-1786) geht das bekannte Wort: „Jeder nach seiner Fasson" zurück, das bis heute nachklingt, wo von der Religion als Privatsache gesprochen wird. Fest eingeprägt hat sich Friedrich Nietzsches (1844-1900) Bild vom tollen Menschen, der mit einer Laterne in der Hand am hellen Mittag Gott sucht und zum Ergebnis kommt: „Gott ist tot“ (vgl. KF 5456). Über Nietzsches wahre Überzeugung wird bis heute diskutiert.

Der kanadische Philosoph Charles Taylor veröffentliche 2007 ein großes Werk mit dem Titel: A Secular Age (Harvard University Press). Es ist kein Plädoyer für eine gott-lose, religions-freie Welt; vielmehr spürt es den Entwicklungen der Religion in nachmittelalterlicher und nachreformatorischer Zeit nach und prüft die heutigen Einflussmöglichkeiten der Religion in der Gesellschaft. Taylor erhielt am 9. November 2019 den Joseph-Ratzinger-Preis. 
Für Taylor ist das heutige Menschenbild, wie zuvor beschrieben, von einem Individualismus geprägt, der letztlich zu einem Atomismus der Einzelnen führt und die Gesellschaft als ganze bedroht. Wörtlich sagt er: „In unseren 'säkularen' Gesellschaften kann man sich uneingeschränkt politisch betätigen, ohne je Gott zu begegnen, also, ohne an einen Punkt zu gelangen, an dem sich die ausschlaggebende Bedeutung des Gottes Abrahams für dieses ganze Unterfangen eindringlich und unverkennbar bemerkbar macht. Die wenigen heute verbliebenen Momente rituellen Verhaltens oder des Gebets stellen kaum noch eine solche Begegnung dar, während dies in früheren Jahrhunderten des Christentums unumgänglich gewesen wäre." ${ }^{6}$

Das säkulare Zeitalter bestimmt er so: „Eine säkulare Epoche ist eine, in der der Niedergang aller über das menschliche Gedeihen hinausgehenden Ziele denkbar wird, besser gesagt: Dieser Niedergang gehört für sehr viele Menschen zum Bereich vorstellbaren Lebens."

Anders gesagt: Der Mensch lebt nur noch aus sich und in sich selbst, und diese Haltung prägt mehr und mehr die Gesellschaft. Entscheidend aber ist für Taylor, dass es nach wie vor Menschen gibt, die sich gegen den Trend der Zeit zur Wehr setzen, für die Wahrheit nicht durch Wahrhaftigkeit, Glaube nicht durch Glaubwürdigkeit, Religion nicht durch Religiosität ersetzt wird, sondern die nach wie vor an Wahrheit und Glaube festhalten.

Wir leben also in einer Welt pluraler Möglichkeiten, sind von vielerlei Kontextfaktoren bestimmt, doch darf man fragen: Ist nicht das negative Erscheinungsbild der weithin verbreiteten Unzufriedenheit letztlich Ausdruck einer verborgenen und nach wie vor vorhandenen und nicht zu stillenden Sehnsucht nach mehr und nach einem letztlich doch Ganz-Anderen?

An dieser Stelle kehren wir nochmals zur Welt unserer Erfahrung zurück. Interessanterweise ist „Erfahrung“ keineswegs nur ein Wort des alltäglichen Lebens und der geschichtlich und wissenschaftlich geprägten Welt. Karl Rahner hat der Erfahrung schon vor Jahren einen prominenten Platz im religiösen Leben des einzelnen Menschen gesichert, und zwar in seinem aktualisierten Verständnis von Mystik. Was Rahner als Zukunftsvision von morgen beschrieben hat, ist aber längst Gegenwart geworden.

Es geht um die bekannten Feststellungen: „Der Fromme von morgen wird ein 'Mystiker' sein, einer 'der etwas erfahren' hat, oder er wird nicht mehr sein, weil die Frömmigkeit von morgen nicht mehr durch die im Voraus zu einer personalen Erfahrung und Entscheidung einstimmige, selbstverständliche öffentliche Überzeugung und religiöse Sitte aller mitgetragen wird, die

\footnotetext{
${ }^{6}$ Zitiert nach Alexander RIEBEL in Die Tagespost [Würzburg] vom 9.11.2019.
} 
bisher übliche religiöse Erziehung also nur noch eine sehr sekundäre Dressur für das religiös Institutionelle sein kann.“7

Dazu stellt sich die Frage: Welche Folgen hat eine solche Sicht heute für die religiöse Unterweisung? In Hamburg strebt man einen religionswissenschaftlichen Unterricht an, an dem alle Religionsgemeinschaften beteiligt sein sollen. Überlegungen zu engerer Kooperation zwischen den christlichen Konfessionen und anderen religiösen Richtungen gibt es auch an staatlichen Universitäten in Deutschland. Dabei wird die christliche Theologie unter der Hand allerdings schnell zu einer Art christlicher Religionswissenschaft. Eine Theologie im Sinne Karl Rahners ist sie dann nicht mehr. Denn nach ihm hat die Theologie immer einen - wie er es nennt - mystagogischen Charakter. Das heißt: Sie muss den Menschen in das Mysterium einführen, das Geheimnis, das in und hinter allem wirkt.

\section{DIE WEITE ${ }^{8}$}

Als zum Priester geweihter Theologe der römisch-katholischen Kirche bin ich persönlich verpflichtet, täglich das Stundengebet zu verrichten. Das heißt im Fachjargon: Ich habe im Laufe des Tages das Brevier zu beten. Es besteht aus Psalmen, Lesungen von Texten der Heiligen Schrift, Anrufungen, Fürbitten und Segensgebeten, die über den Tag verteilt sind. In verschiedenen Klöstern von Männer- und Frauenorden werden die Gebete zu bestimmten Tageszeiten gemeinsam verrichtet.

Mit der Rezitation von Psalmen treten wir in die Gebetswelt Jesu ein. Jesus war, was vielfach vergessen wird, ein Jude ${ }^{9}$, und die Psalmen spiegeln auf eigentümliche Weise das Gebet der Juden wider. Da ist die Rede von der Natur, ihrer Pracht, aber auch ihren Katastrophen, von Hitze und Kälte, von Fluten und Stürmen, aber auch vom Leben der Menschen, von der Sehnsucht nach Gott, aber auch von Kriegen und Ungerechtigkeit, von machtbewussten Königen, korrupten Richtern, falschen Propheten, von Menschen, die treu und verlässlich sind, aber auch von gott-losen Menschen im wörtlichen Sinne des Wortes und solchen, die fremden Göttern anhängen. Bei genauerem Hinsehen sind die Psalmen in vielem ein Spiegelbild unserer Tage. Wir können

\footnotetext{
${ }^{7}$ Karl RAHNER, Schriften zur Theologie (Einsiedeln: Benziger, 1966); Bd: VII 22f. (= Sämtliche Werke: Freiburg: Herder; Bd. 21, 39f.); dazu KF 163f.

${ }^{8}$ Dazu, Denken, das Weite atmet. Text und Kontext in der Theologie, Hg. Günter Riße / Klaus Vellguth (Ostfildern: Grünewald, 2017).

${ }^{9}$ Dazu Hans Waldenfels, „Er war Jude“, in Ders., Rückwärts, 238-257.
} 
uns in ihnen wiederfinden, mit den Ängsten, die uns heute bedrängen, mit den Sorgen, die uns beschäftigen, aber auch mit unseren Freuden, unserem Dank, unserer Hoffnung und Zuversicht.

Mit all dem stehen wir vor Gott. Es gibt aber dann Momente, wo wir freudig rufen können:

- Psalm 18,20: Er führte mich hinaus ins Weite, er befreite mich, denn er hatte Gefallen an mir.

- Psalm 18,29f.: Du, Herr, lässt meine Leuchte erstrahlen, mein Gott, mach meine Finsternis hell. Mit dir erstürme ich Wälle, mit meinem Gott überspringe ich Mauern.

- Psalm 36,4 (ähnlich 108,4): Herr, deine Güte reicht, soweit der Himmel ist; deine Treue, soweit die Wolken ziehen.

Im Buch Deuteronomium 1,30-32 gibt es ein wunderbares Bild: „Der HERR, euer Gott, der euch vorangeht, er wird für euch kämpfen, genauso, wie er vor euren Augen in Ägypten auf eurer Seite gekämpft hat. Das Gleiche tat er in der Wüste, die du gesehen hast. Da hat der HERR, dein Gott, dich auf dem ganzen Weg, den ihr gewandert seid, getragen, wie ein Mann sein Kind trägt, bis ihr an diesen Ort kamt. Trotzdem habt ihr nicht an den HERRN, euren Gott, geglaubt.“

Dieser GOTT, der mich väterlich-mütterlich trägt, wo ich nicht mehr laufen kann, ist der GOTT-mit-uns, der Emmanuel. In der katholischen Liturgie ruft der Vorsteher ihn immer wieder durch seinen Gruß: „Der HERR ist mit euch" in Erinnerung. Wir müssen uns nur eingestehen: Der Anfang unseres Lebens ist unserem Einfluss entzogen. Wir können damit hadern, dass es uns gibt, oder das Leben als Chance und Raum eigener Gestaltung dankbar annehmen. Nehmen wir das Leben an, sollten wir wahrnehmen, dass es neben uns unendlich viele gibt, die in der ähnlichen oder gleichen Lage sind wie wir. Wir können sie als Blockade eigener Entwicklung empfinden, in ihnen aber Begleiter und sogar Weggenossen erkennen. Sie können uns stützen, aber auch wir können ihnen Hilfe und Stütze sein.

Dann ist da das Ende. Ich kann überzeugt sein: Ende ist Ende, danach ist nichts mehr, eben das Nichts, der tödliche Abgrund. Ich kann meinem Leben aus was immer für Gründen ein Ende setzen. Dennoch: Ist es sinnvoll? Und ist es eigentlich nicht sehr egoistisch, von anderen zu verlangen, dass sie mir aktiv zum Tod verhelfen? Ist es nicht menschlicher, mich loszulassen und mich vertrauensvoll dem Ungewissen zu überlassen? Für Karl Rahner war die Tiefe und Weite nicht so weit und so tief, wie wir selbst sie ausmessen, sondern so weit und so tief, wie sie ist. 
Mit solchen Überlegungen sind wir immer noch bei uns Menschen. Wir sind aber immer auch Teil eines uns umfassenden Größeren, der Natur oder - im Sinne der abrahamitischen Religionen: Judentum; Christentum und Islam - der Schöpfung. Gerade in unseren Tagen, in denen so viele hinsichtlich der klimatischen Entwicklungen, aber auch angesichts der weltweit ausgebrochenen Krankheit verunsichert sind, ist Selbstbeherrschung und Demut, das heißt: Selbstbescheidung angesagt. Wir sind nicht die Herren der Schöpfung, sondern zu pfleglichem Umgang mit der Natur aufgerufen (vgl. KF 54-70.438-440). Wir bestimmen letztlich auch nicht über unser Leben. Wie die Existenz des Einzelnen ist alles, auch die Schöpfung von einem Anfang und einem Ende bestimmt, die ihr selbst entzogen sind.

Gerade weil wir in der geschöpflichen Welt immerzu an Grenzen stoßen und doch ahnen oder sogar davon träumen, dass es ein Darüber-hinaus ein Mehr gibt, macht die zusätzliche Botschaft vom Neuen einen Sinn.

\section{DAS NEUE}

Christen zitieren gerne aus der Geheimen Offenbarung Sätze wie: „Siehe, ich mache alles neu" (Offb 21,5). Dabei wird zumeist übersehen, dass es schon im Judentum beim Propheten Jesaja hieß: „Siehe, ich will ein Neues machen; jetzt soll es aufwachsen, dass ihr erfahren werdet, dass ich Weg in der Wüste mache und Wasserströme in der Einöde" (Jes 43,19). Oder bei Ezechiel: „Ich gebe euch ein neues Herz und einen neuen Geist gebe ich in euer Inneres. Ich beseitige das Herz von Stein aus eurem Fleisch und gebe euch ein Herz von Fleisch“ (Ez 35,26).

Es gibt viel weitere Texte wie:

- 2. Petrusbrief 3,13: Gottes Verheißung gemäß erwarten wir einen neuen Himmel und eine neue Erde, in denen die Gerechtigkeit herrscht.

- Geheime Offenbarung 21,1-4: Dann sah ich einen neuen Himmel und eine neue Erde; denn der erste Himmel und die erste Erde sind vergangen, auch das Meer ist nicht mehr. Ich sah die heilige Stadt, das neue Jerusalem, von Gott her aus dem Himmel herabkommen; sie war bereit wie eine Braut, die sich für ihren Mann geschmückt hat. Da hörte ich eine laute Stimme vom Thron her rufen: Seht, die Wohnung Gottes unter den Menschen! Er wird in ihrer Mitte wohnen und sie werden sein Volk sein; und er, Gott, wird bei ihnen sein. Er wird alle Tränen von ihren Augen abwischen: Der Tod wird nicht mehr sein, keine Trauer, keine Klage, keine Mühsal. Denn was früher war, ist vergangen. 
Mit solchen Texten bekommt die Weite eine zusätzliche Perspektive. Zusammen mit der nicht auslotbaren Tiefe erhält sie einen Richtungspfeil in die offene Zukunft. Zu beachten ist, dass die deutsche Sprache zwei Wörter für Zukunft hat: Zukunft und Advent. Ist „Zukunft“ eher eine Phase im Ablauf der Zeiten, ist „Advent“ das ohne unseren Einfluss auf uns Zukommende es mag ein Segen sein oder ein Fluch. Jedenfalls kommt der „Advent“, ob wir es wollen oder nicht. In den abrahamitischen Religionen verbindet sich mit dem Kommenden der Gedanke des Gerichts, das nicht wir selbst oder andere Menschen über uns fällen, sondern dass über uns gefällt wird.

Natürlich kann der einzelne Mensch diese Sicht der Dinge ablehnen. Nur bringt ihm das nichts, weil die volle Zukunft sich menschlicher Verfügung entzieht und sich unabhängig vom Tun des Einzelnen vollzieht. Wo der Mensch sich jedoch auf die hier angesagte Weite und das damit gegebene Andere und Neue bejahend einlässt, hat es Folgen für das aktuelle Leben, das er führt.

Einmal kommt es zu einem neuen Umgang der vielen Ichs miteinander. Lasse ich mich auf das Ich bzw. die Ichs neben mir ein, erkenne ich, dass sie nicht ich sind, sondern in vielfältiger Gestalt er/sie/es, in vielen Fällen Du. Es entsteht das Wir, wir bilden Gemeinschaft, werden zum Volk, zu Völkern.

Dabei wissen wir heute mehr als je zuvor, dass wir in einem Boot sitzen. Das hat nicht zuletzt mit den heutigen Möglichkeiten der Kommunikation zu tun. Ereignisse in der ganzen Welt werden in nie gekannter Schnelligkeit in alle Teile der Welt getragen. Außerdem waren wir nie so mobil wie heute. Das zwingt uns Menschen, neu über die Formen der Kommunikation miteinander nachzudenken.

Die Kommunikation kann in Ablehnung und Abschottung bestehen oder in liebender Zuwendung. Ich kann grundsätzlich gegen alles Fremde und alle Fremden sein, aber auch für alle Menschen. Ich kann Menschen helfen, die meine Hilfe brauchen, kann mich versöhnen, wenn ich mit jemandem in Streit lebe. Meine Freiheit eröffnet mir eine Fülle von Möglichkeiten des Umgangs mit Anderen bis hin zu Fremden und Feinden. In der Offenheit für die anderen entsteht Solidarität, kommt es zum Einsatz für Frieden und Gerechtigkeit auf den verschiedenen Ebenen gesellschaftlichen Lebens. All das ist möglich, wo aus egozentrischer Selbstverliebtheit und Selbst-Beschränkung Selbst-Losigkeit wird.

Wer sich in der Geschichte der Kulturen und Religionen auskennt, weiß um die Bedeutung des Begriffs ,Selbst-Losigkeit“. In den asiatischen Kulturen Indiens, Chinas bis Japan wird die Verneinung des Selbst sowohl rein theoretisch-philosophisch wie aber auch ethisch-praktisch gesehen ${ }^{10}$. Als ethisch-praktische

10 Dazu ausführlich Hans WALDENFELS, Absolutes Nicht, 95-133, 239-249. 
Kategorie erhält die Verneinung des Selbst ihre eigentliche Stärke. Selbst-Losigkeit ethisch aber ist in der abendländischen Welt genauso verständlich wie in Asien und sicher auch in Afrika und anderen Teilen der Erde.

Ein neuer kommunikativer Umgang der Menschen unter einander wirkt sich schließlich auch auf die Einstellung zur Umwelt aus. Er führt zum Einsatz für den Erhalt der Schöpfung und zum pfleglichen Umgang mit der Natur und ihren Ressourcen und mit der Pflanzen- und Tierwelt. Im Sinne der jüdisch-christlichen Bibel ist der Mensch dann nicht nur der Hüter seiner Brüder und Schwestern, sondern auch der Natur und ihres Reichtums.

\title{
LITERATURVERZEICHNIS
}

Denken, das Weite atmet. Text und Kontext in der Theologie, Hg. Günter Riße, Klaus Vellguth. Ostfildern: Grünewald, 2017.

RAHNER, Karl. Schriften zur Theologie. Bd. VII: Zur Theologie des geistlichen Lebens. Einsiedeln: Benziger, 1966 (= Sämtliche Werke. Bd. 23, Freiburg: Herder, 2006).

RIEBEL, Alexander. In Die Tagespost [Würzburg] 9.11.2019. Internetzugang: 26.03.2020. https: //www.die-tagespost.de/gesellschaft/kultur/Gott-lieben-ist-der-Endzweck;art4881,202854

Waldenfels, Hans. Absolutes Nichts. Zur Grundlegung des Dialogs zwischen Buddhismus und Christentum. Mit einem Geleitwort von Keiji Nishitani. Freiburg: Herder, 1976 (erweiterte Version, Paderborn: Bonifatius-Verlag, 2013).

WALDENFELS, Hans. In-Between. Essays in Intercultural and Interreligious Dialogue. Bangalore: Dharmaram Publications, 2011.

WALDENFELS, Hans. Kontextuelle Fundamentaltheologie. 4. Auflage. Paderborn: Verlag Ferdinand Schöningh, 2005 [O Bogu, Jezusie Chrystusie i Kościele - dzisiaj: teologia fundamentalna w kontekście czasów obecnych. Katowice: Księgarnia św. Jacka, 1993].

WALDENFELS, Hans. Rückwärts blickend vorwärts schauen. Zeitbetrachtungen zu Christentum und Menschsein, Religionen, Kulturen und Gesellschaft. Theologische Versuche. Bd. 4. Paderborn: Bonifatius-Verlag, 2016.

\author{
ZRÓŻNICOWANIE I SKOŃCZONOŚĆ CZŁOWIEKA \\ WOBEC BOSKIEJ NIESKOŃCZONOŚCI I OTWARTOŚCI \\ NA TO, CO WIĘKSZE I NOWE
}

Streszczenie

Kartezjańskie „Cogito ergo sum” determinuje nowoczesne myślenia poprzez podkreślenie znaczenia „ego" (,ja”). W związku z tym wielu ludzi żyjących w swej indywidualnej, konkretnej, historycznej sytuacji, ma tendencję do stawania się absolutnym i niezależnym podmiotem i panem własnego życia, myśli i postaw. Poszczególne czynniki ich biografii, takie jak miejsce i data urodzenia, płeć, język, zawód, przynależność religijna itp. określamy (zaczerpniętym ze współczesnej 
egzegezy biblijnej) terminem „kontekst”. Pośród mnogości różnych „ego” zauważamy takie ,ja”, które (z własnej perspektywy) są „,nie-ja”; nazywamy je: „wy” lub „my”.

Następnie opisany jest rozwój nowoczesnej myśli zachodniej w świetle koncepcji „osoby”. W myśli zachodniej „osoba” jest rozumiana głównie jako jednostka, choć filozofia i teologia średniowieczna podkreśla zarówno indywidualność, jak i relacyjność. Trudność w thumaczeniu terminu „osoba” w różnych środowiskach kulturowych ukazana została w odniesieniu do języka japońskiego.

Pełniejsze zrozumienie człowieka osiągamy tylko wtedy, gdy poznamy jego ograniczenia, zwłaszcza w nauce i technice, i gdy przywrócimy poczucie nieskończoności. Kanadyjski filozof Charles Taylor przypomina, że w dzisiejszym świecie spotykamy nie tylko ludzi, którzy całkowicie porzucili wiarę w Boga i żyją w radykalnej autodeterminacji, ale jest także wielu takich, którzy oczekują spełnienia w życiu bezinteresownym, osadzonym w nadziei na nowe życie pochodzące od Całkiem Innego, którego nazywamy Bogiem - i solidarnie działają na rzecz pojednania, pokoju i sprawiedliwości.

Słowa kluczowe: Ego (ja i nie-ja); kontekst; osoba; thumaczenie; kultura europejska i inne; sekularyzm; nauka i technika; przyszłość i spełnienie; głębia i szerokość; otwartość; nowość. 